\title{
Modelling of pulsating mode of fluidization when obtaining organic-mineral fertilizers
}

\author{
Yaroslav Korniyenko, Serhii Haidai, \\ Andrii Liubek, Serhii Turko, Oleksandr Martynyuk
}

\author{
National Technical University of Ukraine \\ "Igor Sikorsky Kyiv Polytechnic Institute", Kyiv, Ukraine
}

Keywords:

Hydrodynamics

Pulsation

Fluidization

Fertilizers

Ash

Article history:

Received 30.10.2016

Received in revised form 29.11.2016

Accepted 27.12.2016

Corresponding author:

Serhii Haidai

E-mail:

GaidaiSS@i.ua

DOI: $10.24263 / 2304-$

974X-2016-5-4-16

\section{Abstract}

Introduction. The objective of this work is mathematical modeling of inhomogeneous hydrodynamic regime of fluidization, which will improve the efficiency of heat and mass transfer in processes of obtaining organic-mineral fertilizers, which include sunflower ash, stimulating and nutritional components.

Materials and methods. The process of inhomogeneous fluidization, which causes an active volumetric mixing of granular material with the intensive circulation in bed, was held in camera of granulator, equipped with a special gas distribution device in the bottom and the directing insertion in the upper part. Measurements of pressure drop in the bed and videofixation of hydrodynamics have been done by using the special equipment.

Results and discussion. An inhomogeneous regime of fluidization is implemented with applying the original gas-distributing device (with a factor of cross-section $\varphi=4.9 \%)$ and the improved chamber of granulator. An intensive macro-mixing of a granular material (with an equivalent diameter $D_{\mathrm{e}}=3.97 \mathrm{~mm}$ and density $\rho_{p}=1450$ $\mathrm{kg} / \mathrm{m}^{3}$ ) is provided with ratio of nominal pressure drop to height of layer $-\Delta P_{b} / H_{0} \geq 8500 \mathrm{~Pa} / \mathrm{m}$ and frequency of pulsations $f=1.67 \mathrm{~Hz}$. The absence of stagnant zones provides the coefficient of granule formation $\psi \geq 90 \%$, and the average specific load of bed's surface by moisture $a_{f}$ $=0.8 \div 0.9 \mathrm{~kg}_{\text {wet }} /\left(\mathrm{m}^{2} \cdot \mathrm{h}\right)$. A chosen mathematical model was modified what allowed to define the conditions of the process considering inhomogeneity in which $25 \%$ of the layer mass is in active phase above the bed with a frequency $f=1.67 \mathrm{~Hz}$. It confirms the results of research with accuracy of $94.8 \%$.

Conclusions. Hydrodynamics without formation of stagnant zones in chamber of granulator was implemented. Modified mathematical model allowed to determine the intensity of an active volumetric circulating mixing that will significantly improve the stability of a granule formation process in dewatering of liquid heterogenous systems. 


\section{— Processes and Equipment of Food Productions -}

\section{Introduction}

Rapid population growth causes an increase in the demand of agricultural products, quality and amount of which depends on agricultural land [1]. However, over $30 \%$ of the world arable lands have been lost as a result of erosion and pollution by chemical fertilizers for the past 40 years [2]. The deterioration of state of the environment compels the humanity to seek ways to reduce the negative impact on the soil [3].

In modern terms to increase yields is advisable to create a complex granulated organicmineral fertilizers that contain mineral nutrients NPK, deoxidizing additives and humic substances, contributing the simultaneous soil formation.

As phosphorus-potassium substances a sunflower ash which is obtained by burning of husk can be used in the production of fertilizers. The husk is a by-product of sunflower oil production, percentage of which in market is constantly increasing, and reached to $6.6 \%$ among 17 oilseeds. This is evidenced by the constant increase of acreage for planting of sunflower in the world and at the year 2016 amounted to $25,640,000 \mathrm{Ha}$ [4].

Content of the main valuable components that are a part of sunflower ash is $93.67 \%$ of the total weight, Table 1, and the rest $6.33 \%-\mathrm{Zn}, \mathrm{C}, \mathrm{Co}, \mathrm{Mn}, \mathrm{Fe}, \mathrm{Mo}$ [5].

The chemical composition of sunflower ash

Table 1

\begin{tabular}{|c|c|c|c|c|c|}
\hline Chemical compounds & $\mathrm{K}_{2} \mathrm{O}$ & $\mathrm{CaO}$ & $\mathrm{MgO}$ & $\mathrm{SO}_{3}$ & $\mathrm{P}_{2} \mathrm{O}_{5}$ \\
\hline wt.\% & 31.40 & 19.07 & 18.58 & 13.68 & 10.94 \\
\hline
\end{tabular}

Dehydration and granulation of a sunflower ash water solution is proposed with an implementation of rotary drum granulators [6-8], but due to the lack of nitrogen-containing components and humic substances the effectiveness of their use reduces. The authors [911] propose to eliminate the aforementioned drawbacks by pressing the mixture composed of ammonium sulfate and humic substances in addition to sunflower ash, but in this case the component distribution is at macro level and finished product have a low strength and great capacity for caking.

To obtain a granular product with desired properties the most effective is technique of fluidization which allows to combine multiple technological stages in one device with the coefficient of heat using more than $50 \%$. An important factor for implementation of this method is hydrodynamics [12].

Effectiveness of the process kinetics depends on the hydrodynamic regime in chamber of granulator, which provides the necessary intensity of renewal the contact surface of phases by moving a considerable mass of granular material.

Therefore, research of hydrodynamic regime of fluidization that provides an active volumetric mixing of granular material with an intensive circulation in bed with absence of stagnant zones in chamber of granulator and on the surface gas-distributing device and significantly to intensify the process by the use of heat carrier with a temperature that is significantly higher than the melting point of nitrogenous components is topical.

The aim of experimental research is to determine the conditions under which the jetpulsating mode of fluidization provides an active volumetric mixing of granular material with an intensive circulation in bed. 


\section{Analysis of scientific works}

Researches of the transfer process in a bubbling mode of fluidization were held in works of D. Gidaspow, J. Davidson $[13,14]$ and other. In the main they considered the jet injection of gas flow with the further movement of gas bubbles formed in layers of granular material with height $H_{0}>1 \mathrm{~m}$.

In particular, the authors [15] propose to improve a layer mixing due to formation of large bubbles $D_{\text {apparatus }} / D_{\text {bubbles }}<1.5$, that in a layer partially moves its part while lifting. Material that is above a layer is sliding due to a presence of stern in a lower part of the bubble. With this is proposed reduction of a step between the gas jets in the gas distribution device. In this can be achieved a merger of bubbles with the formation of a large one, occupying nearly the whole volume of chamber, thus providing a local piston mode of fluidization. However, movement of a granular material into the bottom of an apparatus chamber is significantly slowing and respectively its circulation to.

Regularities of inhomogeneous fluidization were profoundly investigated in the works of scientists [14, 16-18] but most fully the interaction of gas with solid particles in dispersion medium was investigated in the [13].

The author [13] propose a determination of the total pressure drop as the sum of three basic components: pressure drop due to momentum of gas and solid particles, pressure drop due to friction of gas and particle and pressure drop due to the weight of solids, that can be written in differential form as [13]:

$$
\begin{gathered}
\left(\frac{d P}{d z}\right)_{\text {total }}=\left(\frac{d P}{d z}\right)_{\text {momentum }}+\left(\frac{d P}{d z}\right)_{\text {friction }}+\left(\frac{d P}{d z}\right)_{\text {elevation }}, \\
\Delta P_{\text {total }}=\Delta P_{\text {momentum }}+\left(\Delta P_{\text {friction due to gas }}+\Delta P_{\text {friction due to solids }}\right)+\Delta P_{\text {elevation. }} .
\end{gathered}
$$

Pressure drop in the bed due to momentum of gas and solid particles in integral form [13]:

$$
\Delta P_{\text {momentum }}=\left(\varepsilon_{p} \rho_{p} v_{p}^{2}+\varepsilon_{g} \rho_{g} v_{g}^{2}\right) H_{0}
$$

where $\varepsilon_{p}, \varepsilon_{g}$ - void fraction of solid particles and gas; $\rho_{p}, \rho_{g}$ - density of solid particles and gas, $\mathrm{kg} / \mathrm{m}^{3} ; v_{p}, v_{g}$ - velocity of solid particles and gas, $\mathrm{m} / \mathrm{s} ; H_{0}$ - height of the motionless bed, $\mathrm{m}$.

Pressure drop due to friction of gas and of solid particles [13]:

$$
\begin{gathered}
\Delta P_{\text {friction dueto gas }}=\frac{2 f_{g} \varepsilon_{g} \rho_{g} v_{g}^{2} H_{0}}{D_{t}}, \\
\Delta P_{\text {friction dueto gas }}=5.7 \cdot 10^{-2} \frac{1}{D_{t}} \varepsilon_{g} v_{g} \rho_{g} \theta H_{0} \sqrt{g D_{t}},
\end{gathered}
$$

where $f_{g}$ - coefficient of gas friction; $D_{t}$ - diameter of the apparatus, m; $\theta=\left(\varepsilon_{p} \rho_{p} v_{p}\right) /\left(\varepsilon_{g} \rho_{g} v_{g}\right)-$ the loading ratio of solid and gas phases. 


\section{- Processes and Equipment of Food Productions -}

Pressure drop due to the weight of solid particles [13]:

$$
\Delta P_{\text {elevation }}=g\left(\rho_{g} \varepsilon_{g}+\rho_{p} \varepsilon_{p}\right) H_{0} .
$$

Thus, the equation (2) in expanded form:

$$
\begin{aligned}
& \Delta P_{\text {total }}=\left(\varepsilon_{p} \rho_{p} v_{p}^{2}+\varepsilon_{g} \rho_{g} v_{g}^{2}\right) H_{0}+\frac{2 f_{g} \varepsilon_{g} \rho_{g} v_{g}^{2} H_{0}}{D_{t}}+ \\
& +5.7 \cdot 10^{-2} \frac{1}{D_{t}} \varepsilon_{g} v_{g} \rho_{g} \theta H_{0} \sqrt{g D_{t}}+g\left(\rho_{g} \varepsilon_{g}+\rho_{p} \varepsilon_{p}\right) H_{0}
\end{aligned}
$$

\section{Materials and methods}

\section{Experimental installation}

In order to achieve the specified requirements for the granular product was used a specifically developed method of the experiment [19].

Investigation of the hydrodynamic mode of fluidization carried out at the experimental installation of granulator with the chamber sizes $A \times B \times H=0.3 \times 0.11 \times 0.8 \mathrm{~m}$. To create a jetpulsating mode of fluidization, the chamber of granulator in a bottom part is equipped with the gas distribution device (GDD) of a slit type [Patent of Ukraine № 109509 IPC B01J 8/44. Gas distribution device of a fluidized bed apparatus], and the with the guiding insertion at the top [Patent of Ukraine № 95431 IPC B01J 8/44. Section of fluidized bed apparatus]. The cross-section coefficient of GDD is $\varphi=4.9 \%$, and a step between the slits, relatively to a chamber'r's width $-t=0.4 A[20]$.

\section{Materials}

As a granular material was applied a polydisperse granular product on the basis of sunflower ash and ammonium sulfate with additives of humins containing components.

It was obtained by the application of dehydration of composite liquid systems in the apparatus of a fluidized bed [Patent of Ukraine № 4465. IPC C05 G 1/00. The method of granulated organic-mineral fertilizers production]. Equivalent diameter of particles $D_{\mathrm{e}}=3.97$ $\mathrm{mm}$ and density $-\rho_{p}=1450 \mathrm{~kg} / \mathrm{m}^{3}$. Mass of loaded into the apparatus bed of granules was $M_{b e d}=8.2 \mathrm{~kg}$. From this mass the bed height was determined as $H_{0}=0.32 \mathrm{~m}$ and the nominal hydrostatic pressure $\Delta P_{\text {nom. }}=2780 \mathrm{~Pa}$ at porosity $\varepsilon_{0}=0.4$.

\section{Measuring complex}

Pressure drop in the bed was continuously measured by the computerized system with using of low pressure sensors MPXV7007DP with an accuracy $\pm 0.1 \mathrm{~Pa}$ and the frequency of 63 measurements per second $(63 \mathrm{~Hz})$ connected to the computer via the controller Arduino Pro Mini. The scheme of placement devices and sensors for fixing data is shown in Figure 1. 

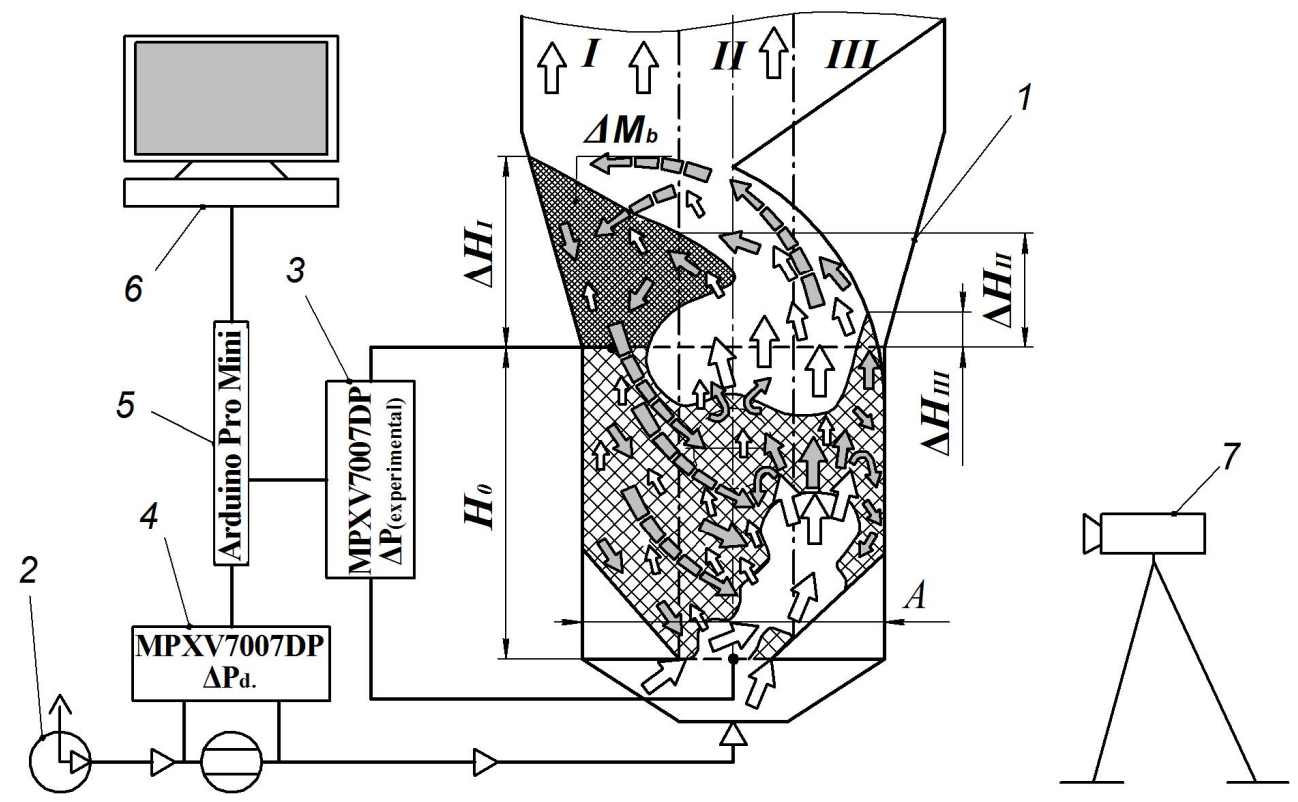

Figure 1. The scheme of computerized system for measuring the pressure drop in the experimental installation

1 - fluidized bed granulator; 2 - gas blower; 3, 4 - low pressure sensors;

5 - controller; 6 - computer; 7 - video camera

The porosity of bed was determined with the use of photo-analysis of the bed state in time with step $\Delta \tau=0.04 \mathrm{~s}$. The calculation of velocitiesthat are included in equation (7) was carried out by the known dependencies of Reynolds number from Archimedes number $(\operatorname{Re}=f(\mathrm{Ar}))[13,14]$.

\section{Results and discussion}

\section{Physical modeling of inhomogeneous fluidization}

Apparatus is roughly divided into three zones $I-I I I$ (Figure 2, a) with almost the same

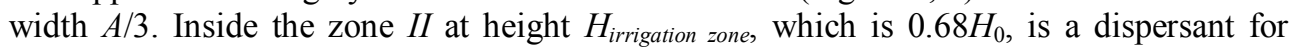
filing the liquid phase.

The basic technical idea is to organize such interaction of gas phase with solid particles, which would ensure an active granular material passing through the irrigation zone $(I I)$, relaxation $(I)$, intensive heat transfer $(D)$, located directly at the surface of GDD, and upward flow through the zone (III) - airlift (Figure 2).

The gas jet through the slits of GDD is filing into a chamber of granulator by two streams: horizontal - point $\boldsymbol{p}$ and at the angle $\alpha$-point $\boldsymbol{k}$, (Figure 2, b).

Long range of a gas jet in horizontal direction (p. p) $x_{\text {hor }}$ depends on the volume flow rate of fluidizing agent $x_{\text {hor. }}=f(V)$ and in active mode is almost equal to the width of fluidization zone $I I(A / 3)$. Vertical part of the jet (from p.p) is connecting to the stream (from p. $\boldsymbol{k}$ ) at the height $\Delta+y_{f}$. As a result of this method of filing the fluidizing agent at the height of the torch $y_{f}$, that comes out of p.k there is horizontal coalescence of gas phase in 
zone III. This further causes an intense inertial ejection of the granular material into space above the bed. Velocity of these particles must be sufficient for moving to the surface of zone $I$ (line segment $\boldsymbol{b} \boldsymbol{c}$ ) when contacting with the insert 3 (Figure 2).

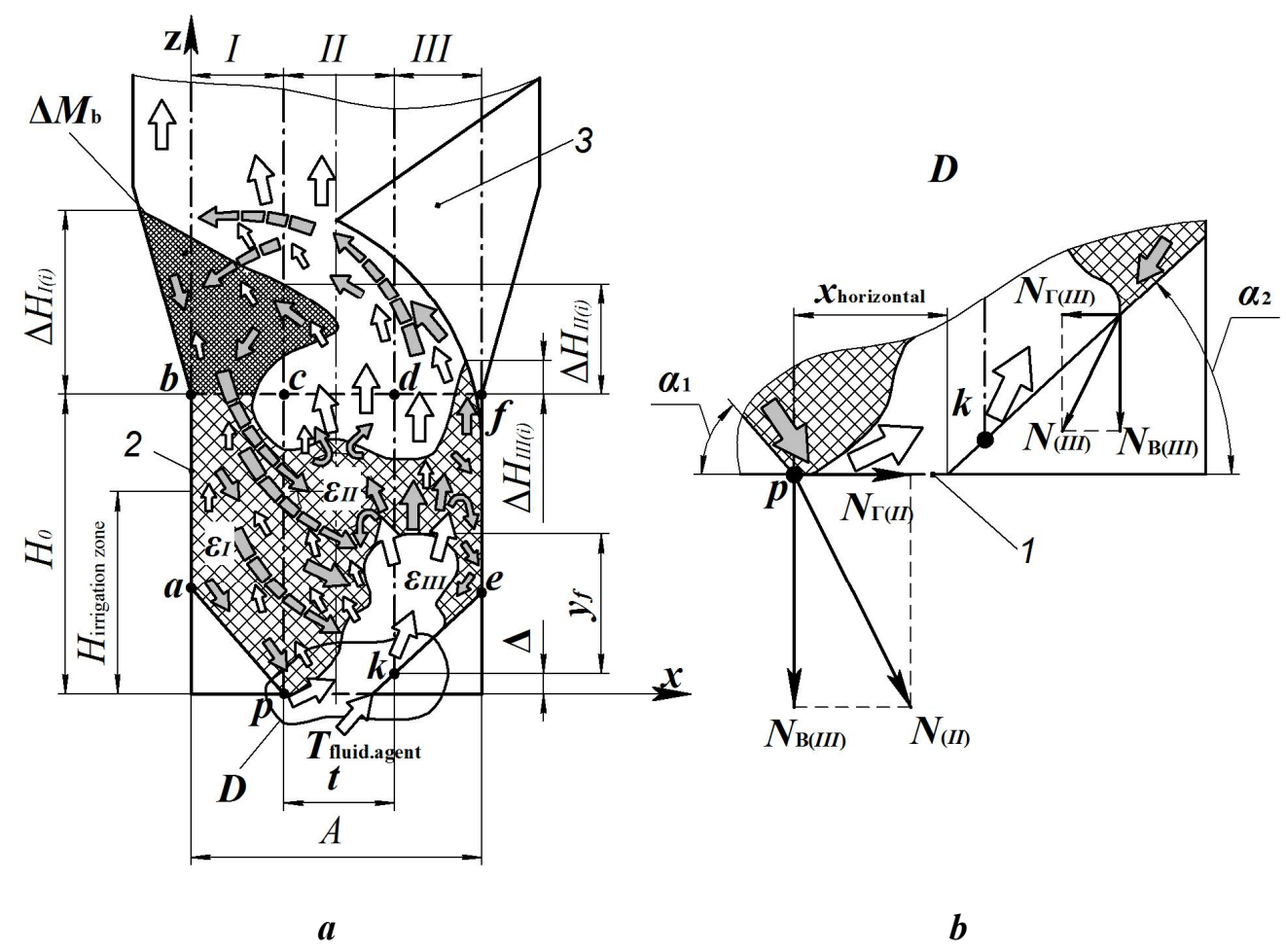

Figure 2. Physical model of the jet-pulsating mode of fluidization $a$ - the flows scheme in chamber of the apparatus; $b$ - scheme of forces acting on the gas jet in working area GDD; 1 - gas distribution device (GDD);

2 - chamber of granulator; 3 - guiding insertion;

$I$ - zone of downward movement $(a, b, c, p) ; I I$ - transition zone $(p, c, d, k)$;

$I I I$ - zone of an upward flow (the ascending zone) $(k, d, f, e) ; D$-zone of an intense heat exchange

As a result, there is a significant pulsational increase of a bed height in zone $I$ to magnitude $\Delta H=(0.4 \div 0.8) H_{0}$ (Figure 2$)$ and as a result the hydrostatic pressure in zone of the downward movement $I$ (p. p) is significantly increasing. This leads to shifting of large mass of granular material into transition zone $I I$, through the line $c p$ as the pressure $N$ acting on the p. $\boldsymbol{p}$ increases due to it's vertical and horizontal components $\left(N_{\text {hor. }}=K \cdot N_{\text {vertical }}\right)$, (Figure 2 , b). For this reason, further is happening the displacement of a gas torch trajectory (that comes out of p. p) and its union with stream from p. $\boldsymbol{k}$. Thus, gas heat carrier that is injected into the zone $I I I$ creates a local piston-mode of fluidization $\left(V_{\text {bubbles }}=0.33 \cdot V_{\text {apparatus }}\right)$ the zone of an upward flow III by increasing of pressure of material in zone $I$ and $I I$. 


\section{— Processes and Equipment of Food Productions-}

This physical model of inhomogeneous fluidization (Figure 2), is possible at velocity of particle moving out of the bed $W_{\text {moving }}>2 \mathrm{~m} / \mathrm{s}$, and is calculated from the equation, $\mathrm{m} / \mathrm{s}$, [21]:

$$
W_{\text {moving }}=\left(2 \cdot g \cdot H_{0}\right)^{1 / 2} \text {. }
$$

\section{Justification of the mathematical model}

With taking into account the developed physical model in the momentum equation (3) and in the pressure loss equation (6) for $H_{0}$ is necessary to enter a variable additional of material bed height $H_{\text {variable }}=f(\tau)$ that is transferred into the zone I. This depends on the intensity of the hydrodynamic mode. Accepted that for each moment of time $\varepsilon_{p}+\varepsilon_{g}=1$.

taking into account of these assumptions, an equation (7) takes the form:

$$
\begin{aligned}
& \Delta P_{\text {total }}=\left(\varepsilon_{p} \rho_{p} v_{p}^{2}+\varepsilon_{g} \rho_{g} v_{g}^{2}\right)\left(H_{0}+H_{\text {variable }}\right)+\frac{2 f_{g} \varepsilon_{g} \rho_{g} v_{g}^{2} H_{0}}{D_{t}}+ \\
& +5.7 \cdot 10^{-2} \frac{1}{D_{t}} \varepsilon_{g} v_{g} \rho_{g} \theta H_{0} \sqrt{g D_{t}}+g\left(\rho_{g} \varepsilon_{g}+\rho_{p} \varepsilon_{p}\right)\left(H_{0}+H_{\text {variable }}\right)
\end{aligned}
$$

\section{Experimental studies of hydrodynamic mode}

The dynamics of pressure drop fluctuations in bed with volumetric flow of fluidizing agent $V=0.039 \mathrm{~m}^{3} / \mathrm{s}$ and number of fluidization $K_{\mathrm{w}}=1.02$ as a graphical dependency and photographs of layer state in local extremums $\Delta P$ are presented on Figure 3, 4 .

Maximum values of pressure drop in the bed at a $K_{w}=1.02$ are lower then $\Delta P_{\text {nom. }}$. This indicates the absence of inertial mass transfer of bed.

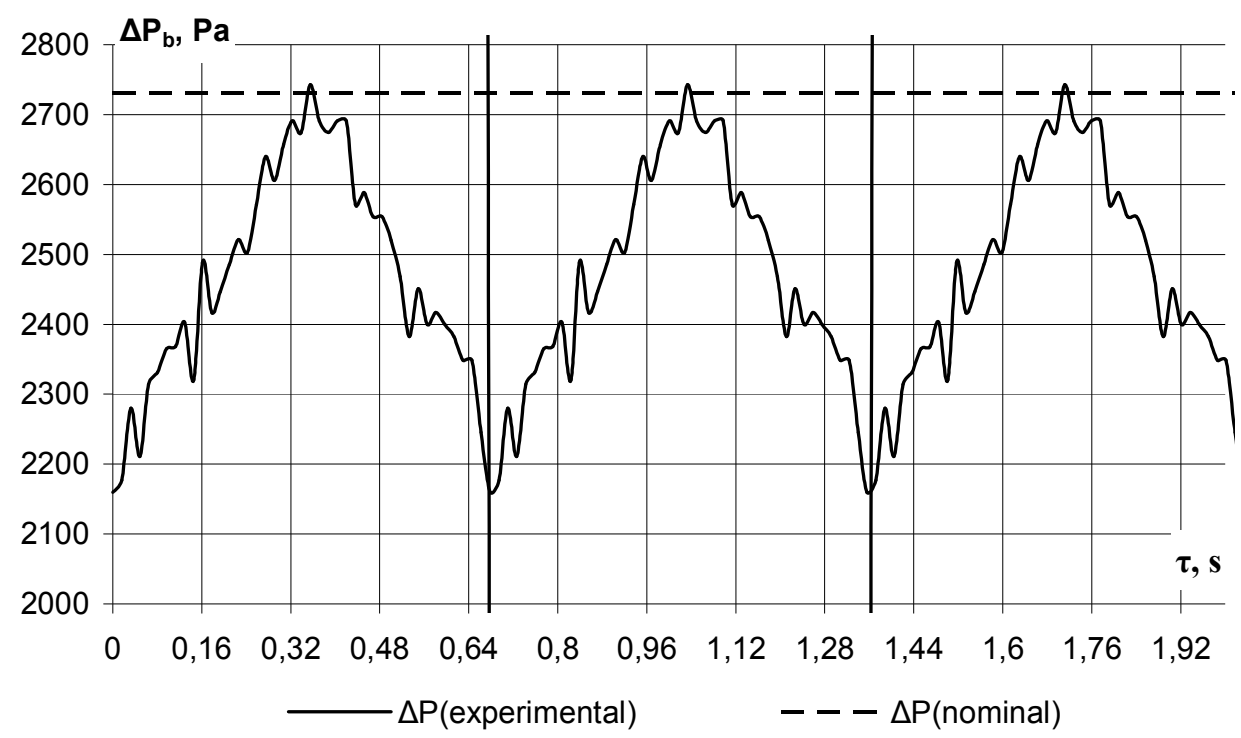

Figure 3. Experimentally determined dynamics of pressure drop changes in bed for $H_{0}=0.32 \mathrm{~m}, K_{\mathrm{w}}=1.02$ and frequency of pulsations $f=1.47 \mathrm{~Hz}$ 


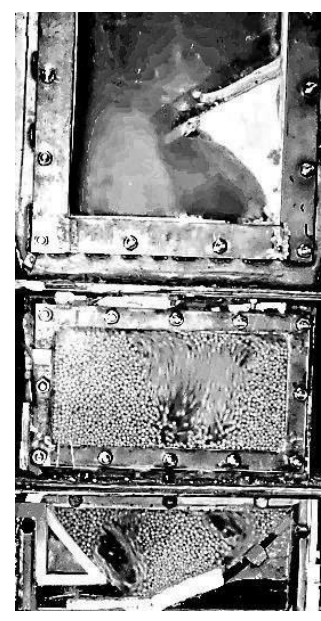

$\mathrm{A}: \boldsymbol{\tau}=\mathbf{0 . 0 0 \mathrm { S }}$

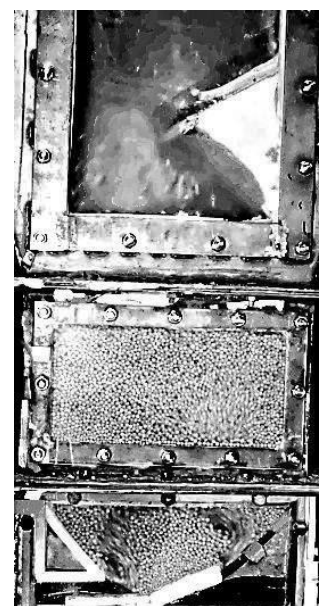

B: $\tau=0.34 \mathrm{~s}$

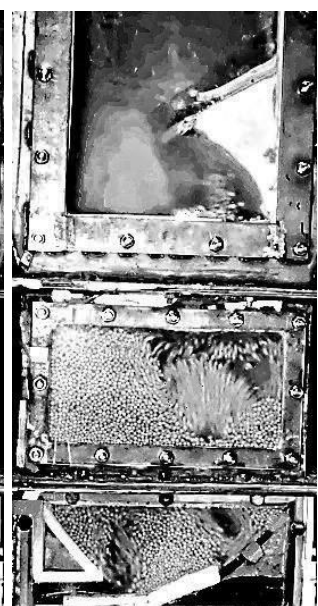

$C: \tau=0.68 \mathrm{~s}$

Figure 4. Experimentally determined photofixation of bed at minimum and maximum values of pressure drop for $H_{0}=0.32 \mathrm{~m}, K_{\mathrm{w}}=1.02$ and frequency of pulsations $f=1.47 \mathrm{~Hz}$

The minimum values of $\Delta P_{b}$ (Figure $\left.4 A, C\right) \Delta P_{b}<\Delta P_{\text {nom. }}$ comply with the conditions in which vertical jets, emerging from two slits are combined into one at height $y_{f}=80 \div 100 \mathrm{~mm}$ [12] and locally pass through a bed of granular material, causing a small inertial particle removal (point $B$ ), that is characterized by a slight increase of $\Delta P_{\max }-\Delta P_{\text {nom. }} \leq 100 \mathrm{~Pa}$. Thus the kinetic energy of particles that are moving from the bed is insufficient to interaction with the directing insert 3, Figure 1. Therefore, moving of granular material from the zones $I I$ and $I I I$ into a zone $I$ do not occur. That means that there is no motion of material into space above the bed.

When increasing the energy of the gas flow injected through the slits of GDD to the bed of granular material, for values of $V=0.0528 \mathrm{~m}^{3} / \mathrm{s}$ and $K_{\mathrm{w}}=1.37$, Figure 5 , pulsation frequency increases from $f=1.47 \mathrm{~Hz}$ to $f=1.67 \mathrm{~Hz}$, that is confirmed by the photographs of bed condition in local extremes, Figure 6.

For these conditions the amplitude of exceeding the nominal pressure $\Delta P_{\text {nom. }}=2780 \mathrm{~Pa}$ is $\Delta P_{\text {ampl. }}=670 \mathrm{~Pa}$, that indicates moving of the particle mass into space above the bed. This mass is equivalent $\Delta M_{b}=\left(\Delta P_{\text {ampl. }} \cdot A \cdot B\right) / \mathrm{g}$ and in this case is $2.01 \mathrm{~kg}$.

Value of $\Delta P_{b}$ is considered as parameter that determines mass of the bed. So in this case the ratio of $\Delta P_{\max } / \Delta P_{\text {nom. }} \geq 0.25$ indicates that the number of cycles required to exchange of all the mass of bed $n_{\mathrm{c}}=4$ implemented by $\tau=2.4 \mathrm{~s}$. It means, that the system works in auto-oscillatory mode [15]. In this case, energy that enters with the fluidizing agent is enough for implementation of the jet-pulsating mode of fluidization with intensive moving of particulates out of bed and efficient transport of it into the zone $I$ (Figure 5, 6). This It confirms position of the physical model.

The minimum values of $\Delta P_{\mathrm{b}}$ (Figure 5,6$)$ are $0.8 P_{\text {nom }}$ and appear as a result of moving the material out of the bed (Figure 6) - points $A$ and $C$. The height of bed in zone $I$ significantly increases with a simultaneous movement of granular material into the middle of zone $I I$ and to the lower part of zone $I$ (Figure 2). 


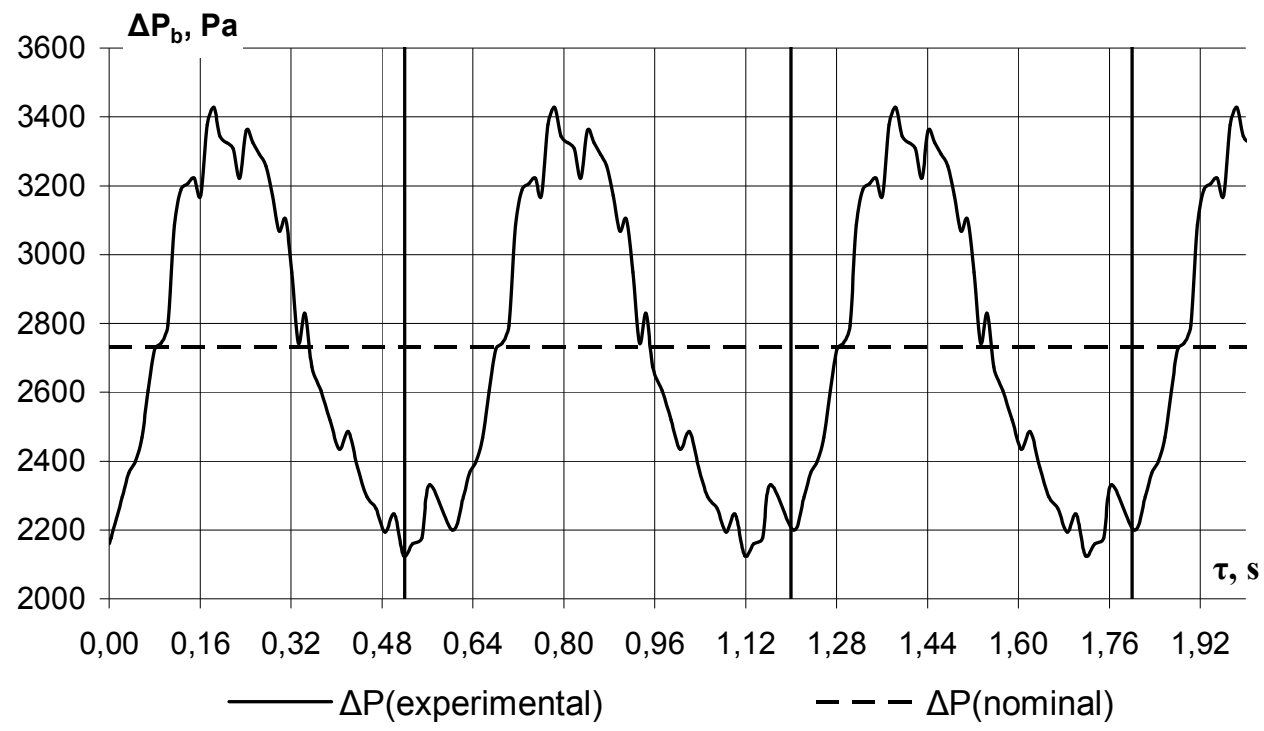

Figure 5. Experimentally determined dynamics of pressure drop changes in bed for $H_{0}=0.32 \mathrm{~m}, K_{\mathrm{w}}=1.37$ and frequency of pulsations $f=1.47 \mathrm{~Hz}$

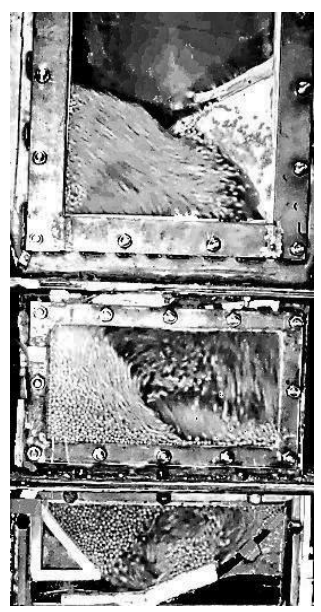

$\mathrm{A}: \boldsymbol{\tau}=\mathbf{0 . 5 2} \mathrm{s}$

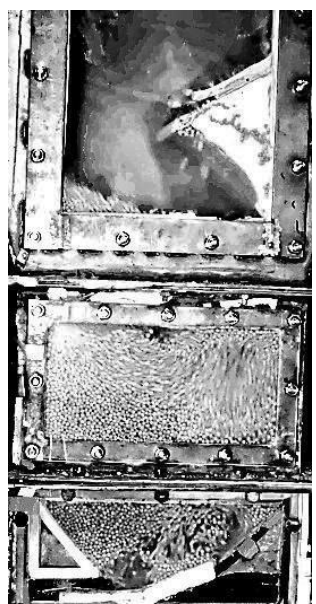

B: $\boldsymbol{\tau}=\mathbf{0 . 8 0} \mathrm{s}$

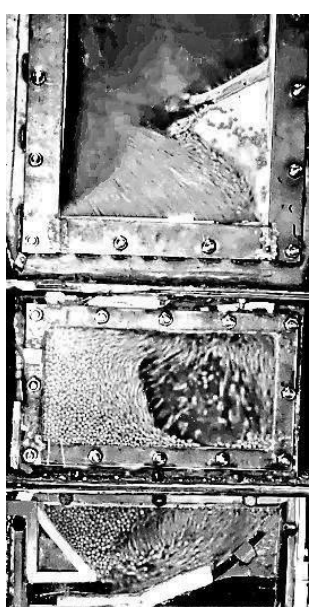

$C: \tau=1.18 \mathrm{~s}$

Figure 6. Experimentally determined photofixation of bed at minimum and maximum values of pressure drop for $H_{0}=0.32 \mathrm{~m}, K_{\mathrm{w}}=1.37$ and frequency of pulsations $f=1.47 \mathrm{~Hz}$ 


\section{— Processes and Equipment of Food Productions -}

The peak of pressure drop is observed when energy of the injected gas phase is expended on formation of gas bubbles i.e.:

$$
\Delta P_{\text {max }}-\Delta P_{\text {nom }}=\left(1-\varepsilon_{0}\right) \mathrm{g} D_{\text {bubbles }}
$$

where $D_{\text {bubbles }}$ - vertical size of voids formed in the bed, $\mathrm{m}$.

The effect of oscillatory jet-pulsing mode is reinforced by presence of pulsations expenditure of gas-blower (Figure 7) that occur in opposite phase against the bed pulsations.

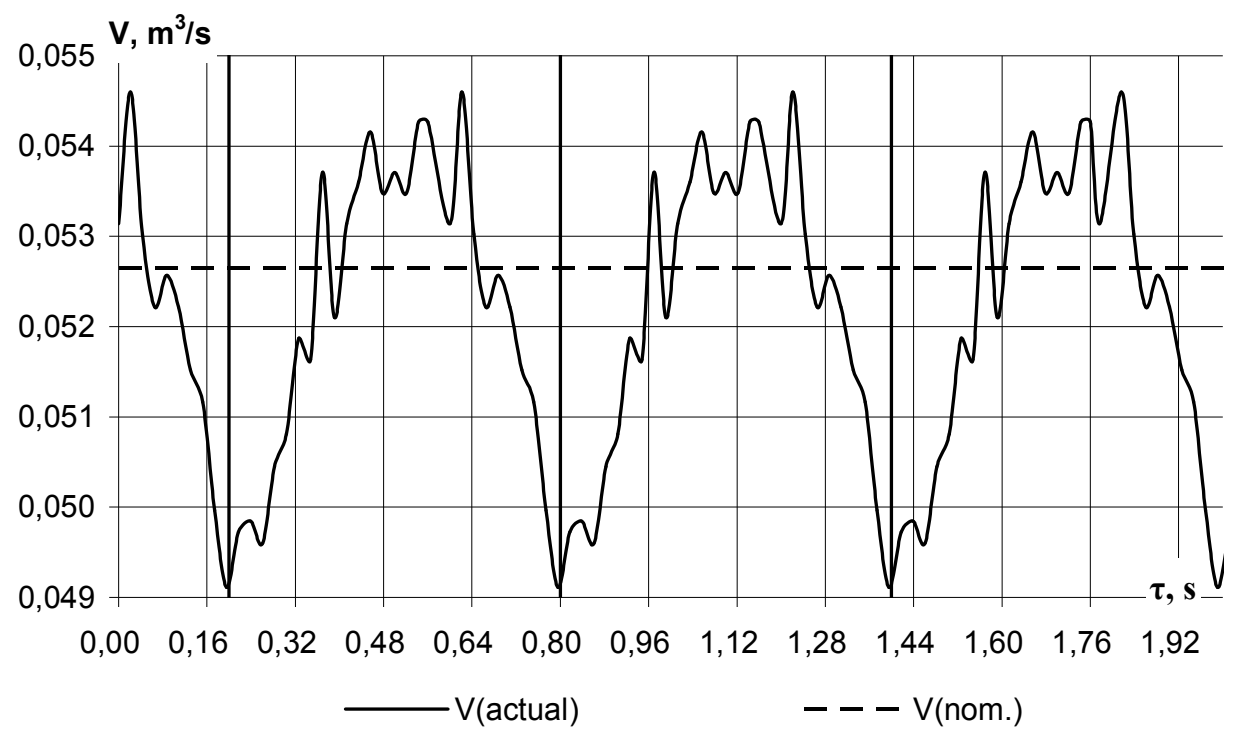

Figure 7. Experimental obtained values of volumetric flow changes when filing fluidizing agent for $K_{\mathrm{w}}=1.37$ and frequency of pulsations $f=1.67 \mathrm{~Hz}$

At the same time, the volumetric flow value of fluidizing agent is changing within the limits $0.049 \mathrm{~m}^{3} / \mathrm{s} \leq \mathrm{V} \leq 0,0545 \mathrm{~m}^{3} / \mathrm{s}$ with a frequency $f=1.67 \mathrm{~Hz}$.

\section{Analysis of the dynamic changes of the void fraction}

For calculating the dynamics of changes of the total pressure drop according to equation (9) a bed void fraction was defined. Dynamics of the void fraction change in selected zones and the average values are shown on Figure 8. 


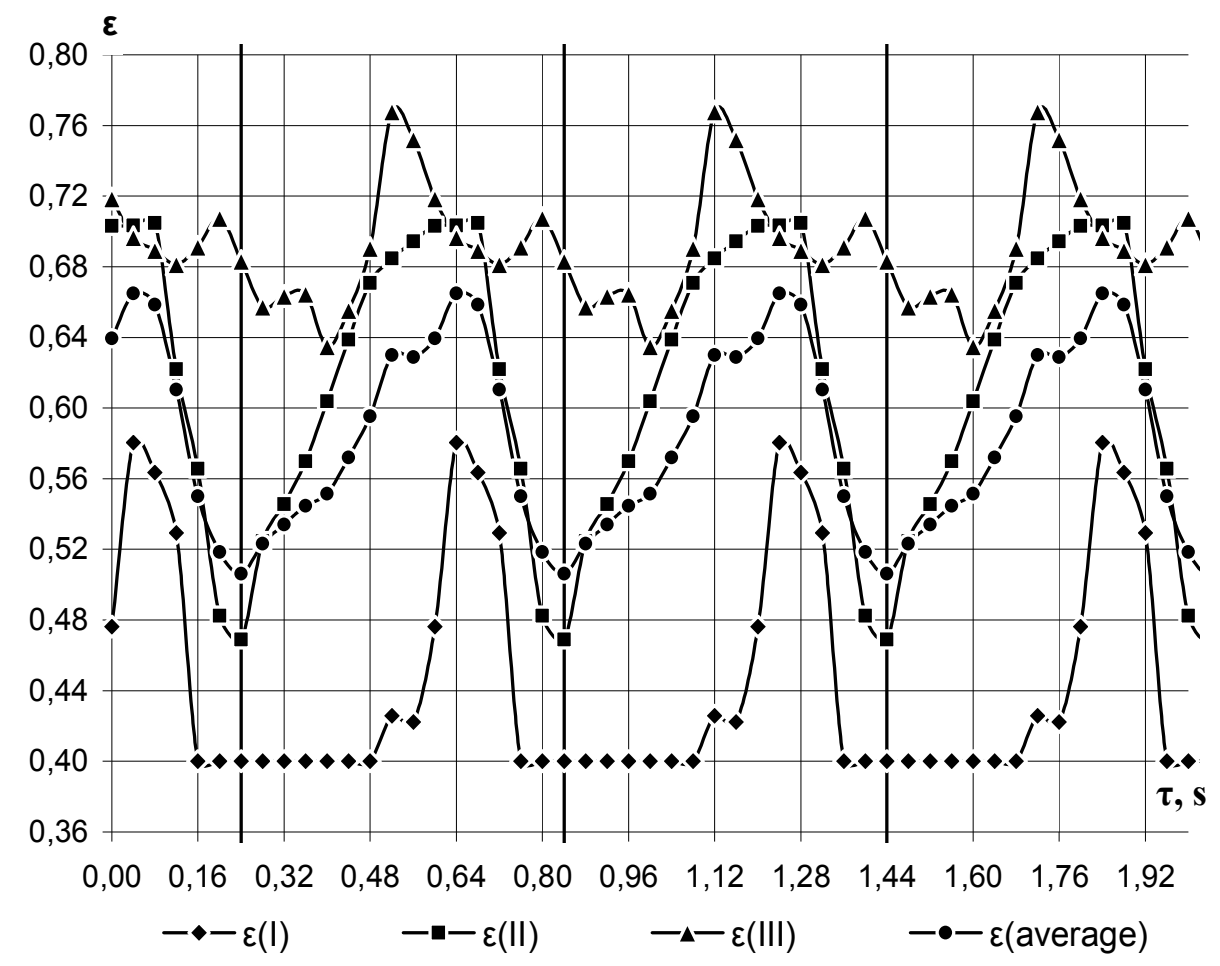

Figure 8. Dynamics of the void fraction change in selected zones $(I, I I$ and $I I I)$ and the average values in chamber of an apparatus for $H_{0}=0.32 \mathrm{~m}, K_{\mathrm{w}}=1.37$ and frequency of pulsations $f=1.47 \mathrm{~Hz}$

The selected time interval $0.24 \mathrm{~s} \leq \tau \leq 0.84 \mathrm{~s}$ is a typical cycle that is repeated in further. So in the ascending zone $I I I$ void fraction is changed with pulsations. So in the ascending zone $I I I$ the void fraction is changed pulsatingly within the limits of $0,63 \leq \varepsilon_{I I I} \leq 0,77$ with the pronounced local extremes. The change of voids in zone $I I \quad 0.46 \leq \varepsilon_{I I} \leq 0.70$ is also in pulsating mode with coincidences of the maximum values at the time interval of depending $\varepsilon_{2}=f(\tau)$ for zone $I I I$. In zone $I$ a practically constancy values of void fraction at the level $\varepsilon_{I}=0.4$ is observed, except certain cases $\left(\varepsilon_{I}=0.58\right)$, when the void fraction reaches the maximum values in adjacent areas. The calculated average values of the void fraction in the bed varies within the limits $0.5 \leq \varepsilon_{\text {average }} \leq 0.65$. It is logical that the frequency of changes void fraction is equal to the frequency of pulsations $f=1.67 \mathrm{~Hz}$.

\section{Analysis of the dynamic changes in the height of bed}

The experimentally determined height of bed in three zones taking into account a local growth of bed due to changes of void fraction is shown in Figure 9. 


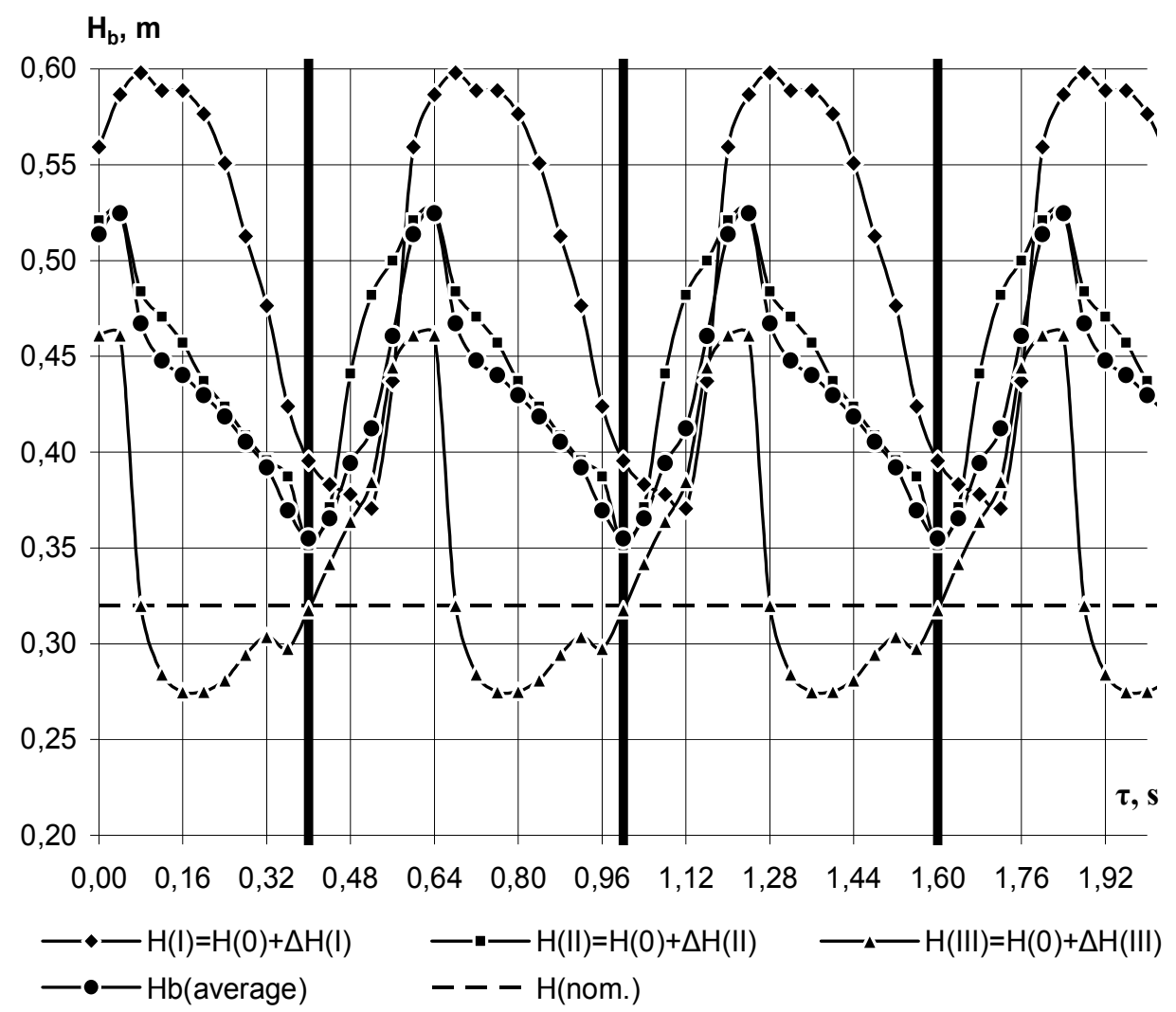

Figure 9. Dynamics of the bed height change in selected zones (I, $I I$ and $I I I)$ and the average values in chamber of an apparatus for $H_{0}=0.32 \mathrm{~m}, K_{\mathrm{w}}=1.37$

and frequency of pulsations $f=1.47 \mathrm{~Hz}$

Dynamics of the bed height change confirms the pulsating movement of the material mass in bed from zones $I I$ and $I I I$ into zone $I$. Thereby increasing the height of bed in zone of downward movement $(I)$ to magnitude $I \Delta H_{(I) \max }=280 \mathrm{~mm}$ with frequency $f=1.67 \mathrm{~Hz}$ causes an increase in weight of bed in a zone I and an appropriate increase of vertical and horizontal components of material's pressure on the gas torch in p.p and $\boldsymbol{p} \boldsymbol{c}$ lines, Figure 2. This provides an increase of the horizontal jet range, $x_{\text {hor. }}$, and therefore reduces the probability of formation of stagnant zones on the work surface of GDD.

\section{Verification of mathematical model}

Based on the results of experimental studies by defined values of void fraction of the bed of granular material, Figure 8, and its height, Figure 9, by equation (9) the values of the total pressure drop of bed are calculated $\Delta P_{\text {total }}$. Comparison of the results of solving mathematical model with experimental data $\left(\Delta P_{\text {experimental }}\right)$ and with nominal value $\Delta P_{\text {nom. }}$ is shown on Figure 10. The comparison shows the satisfactory convergence with the correlation coefficient $\sigma=5.2 \%$. 


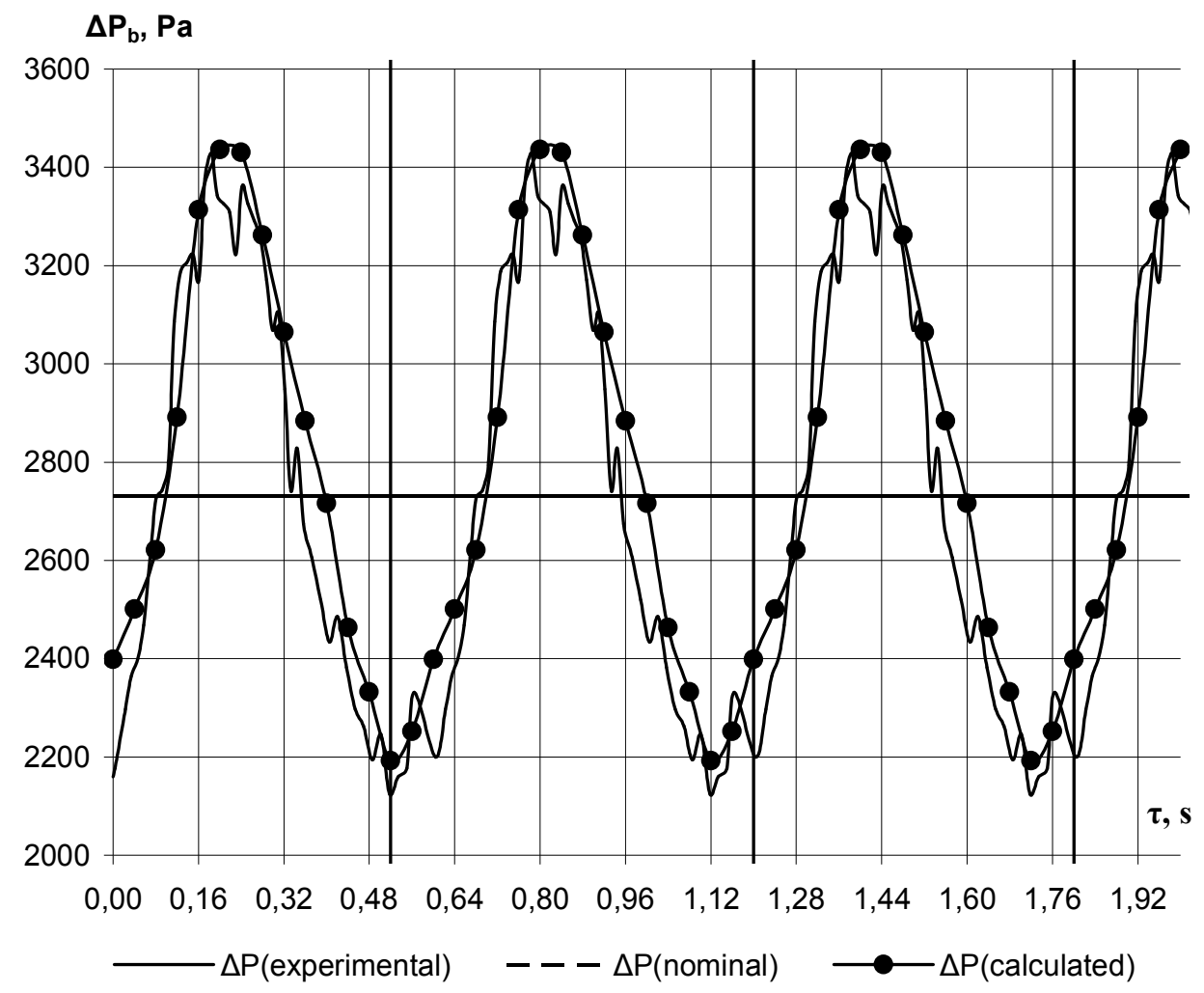

Figure 10. Comparison of the results of solving mathematical model with experimental data of the total pressure drop of bed for $H_{0}=0.32 \mathrm{~m}, K_{\mathrm{w}}=1.37$ and frequency of pulsations $f=1.47 \mathrm{~Hz}$

Result of the work is that theoretically substantiated and experimentally proved that applying of the jet-pulsating mode of fluidization allowed to provide an intense circulation of granular material in the apparatus at values $\Delta \mathrm{P}_{\mathrm{b}} / \mathrm{H}_{0} \geq 8500$ for an equivalent diameter $D_{\mathrm{e}}=3.97 \mathrm{~mm}$ with the minimum value of fluidization number $K_{\mathrm{w}}=1.37$.

\section{Conclusion}

Mathematical model of hydrodynamic regime of fluidization allows to calculate the intensity of the circulating mixing in bed what is necessary to provide a stable kinetics of the process of obtaining complex granular organic-mineral fertilizers.

\section{References}

1. Ban Ki-moon (2016), In safety and dignity: addressing large movements of refugees and migrants, United nations, available at: https://documents-ddsny.un.org/doc/UNDOC/GEN/N16/112/62/PDF/N1611262.pdf?OpenElement 


\section{— Processes and Equipment of Food Productions-}

2. FAO (2015), Crop production and natural resource use, available at: http://www.fao.org/docrep/005/y4252e/y4252e06.htm

3. J. Foley, R. DeFries, G. Asner, C. Barford, G. Bonan, S. Carp (2005), Global Consequences of Land Use, Science, 309 (5734), pp. 570-574.

4. A. Sayduta, S. Erdoganb, A. Beycar Kafadarb, C. Kayab, F. Aydinb (2016), Candan Hamamcib Process optimization for production of biodiesel from hazelnut oil, sunflower oil and their hybrid feedstock, Fuel, 183(1), pp. 512-517.

5. Paleckiene R., Sviklas A., Slinksiene R., Streimikis V. (2010), Complex Fertilizers Produced from the Sunflower Husk Ash, Polish J. of Environ. Stud., 19(5), pp. 973979.

6. Pozin M. (1974), The technology of mineral salts, Chemistry, Leningrad.

7. Obraniak A., Gluba T. (2012), Model of energy consumption in the range of nucleation and granule growth in drum granulation of bentonite, Physicochemical Problems of Mineral Processing, 48(1), pp. 121-128.

8. Degreve J., Baeyens J., Van de Velden M., De Layet S. (2006), Sprayagglomeration of NPL fertilizer ia a rotating dram granulator, Powder Technology, 163, pp. 188-195.

9. Gavin M. Walker (2007), Drum granulation processes, Handbook of Powder Technology, 11, pp. 219-254.

10. Paleckiene R., Sviklas A. M., Slinksiene R., Streimikis V. (2010), Complex Fertilizers Produced from the Sunflower Husk Ash, Polish Journal of Environmental Studies, 19 (5), pp. 973-979.

11. Xue B.C., Hao Q., Liu T., Liu E.B. (2013), Effect of process parameters and agglomeration mechanisms on NPK compound fertiliser, Powder Technology, 247, pp. 8-13.

12. Kornienko Y., Gaidai S., Martyniuk A. (2014), Improved process to obtain granular humic fertilizers, available at: http://ela.kpi.ua/handle/123456789/11943

13. Dimitry Gidaspow (1994), Multiphase flow and fluidization: continuum and kinetic theory descriptions with applications, United Kingdom Edition, London.

14. Davidson J., Harrison D. (1974), Fluidization, Chemistry, Moscow.

15. Tuponogov V., Ryzhkov A., Baskakov A, Obozhyn O. (2008), Relaxation oscillations in a fluidized bed, UPI. hermophysics and Aeromechanics, 15(4), pp. 643-657.

16. Stroh A., Alobaid F., Hasenzahl M.T., Hilz J., Ströhle J., Epple B. (2015), Comparison of three different CFD methods for dense fluidized beds and validation by a cold flow experiment, Particuology, 862, pp. 245-259.

17. Tianyu Wang, Tianqi Tang, Yurong He, Hongliang Yi (2016), Analysis of particle behaviors using a region-dependent method in a jetting fluidized bed, Chemical Engineering Journal, 283, pp. 127-140.

18. Oevermann M., Gerber S., Behrendt F. (2009), Euler-Lagrange DEM simulation of wood gasification in a bubbling fluidized bed reactor, Particuology, 7, pp. 307-317.

19. Korniyenko Y., Hayday S., Semenenko D., Martynyuk O. (2013), Hranul'ovani azotno-kal'tsiyevo-huminovi tverdi kompozyty, modyfikovani bentonitom. Protses oderzhannya, Khimichna promyslovist' Ukrayiny, 5, pp. 46-51.

20. Buevich J., Minaev G. (1984), Jet fluidization, Chemistry, Moscow.

21. Sasic S., Leener B., Johnsson F. (2005), Fluctuation and waves in fluidized bed systems: the influence of the air-supply system, Powder Technology, 153, pp.176195. 